\title{
The Application of the Semi-quantitative Risk Assessment Method to Urban Natural Gas Pipelines
}

\author{
YongQiang BAI*, LiangHai LV and Tong WANG \\ Beijing Municipal Institute of Labour Protection, Beijing of china
}

Received 15 May 2013; Accepted 25 July 2013

\begin{abstract}
This paper provides a method of semi-quantitative risk assessment for urban gas pipelines, by modifying Kent analysis method. The influence factors of fault frequency and consequence for urban gas pipelines are analyzed, and the grade rules are studied on. The grade rules of fault frequency and consequence for urban natural gas pipelines are provided. Using semi-quantitative risk matrix, the risk grade of the urban gas pipelines is obtained, and the risk primary sort for gas pipelines can be accomplished, so as to find out the high risk pipeline unit.
\end{abstract}

Keywords: urban gas pipelines, semi-quantitative, risk assessment, fault frequency, consequence

\section{Introduction}

Urban gas pipeline is a part of the urban infrastructures. Because of the concentration of popularity and buildings, heavy casualties and tremendous economy loss of property will be caused when urban pipelines leak and explosion accident happens. Recent years, disastrous fire and explosion accidents because pipelines leak are increasingly frequent in the world, and caused more and more casualties and economy losses. Risk management of gas pipelines refers to assess the risk of urban gas pipelines operation, and control the risk of urban gas pipelines operation within acceptable limits, so as to decrease accident rate.

There are qualitative risk assessment, semi-quantitative risk assessment and quantitative risk assessment. Now, because of the deficiency of historical data, it is difficult to adopt quantitative risk assessment for gas pipelines [1]. Kent [2] analysis method is the completely semi-quantitative risk assessment method for long-distance transmission pipelines. It is different between for long-distance transmission pipelines oil and gas pipelines and urban gas pipelines. This paper provides a correction risk assessment method based on Kent analysis method. In the new method, risk matrix [3] is introduced, and the indexes of fault frequency and consequence for urban natural gas pipelines are established.

\section{Semi-quantitative risk assessment method for urban gas pipelines}

The fault frequency and consequence constitute the risk of urban gas pipelines $[4,5]$. Through the risk level analysis for the unit of gas pipelines and preliminary risk ranking, the

\footnotetext{
* E-mail address: byqiang2001@163.com

ISSN: 1791-2377 @ 2013 Kavala Institute of Technology. All rights reserved.
}

key units for further quantitative analysis could be determined. Figure.1 indicates the semi-quantitative risk assessment procedure of urban gas pipelines. The main principles and applicable conditions are

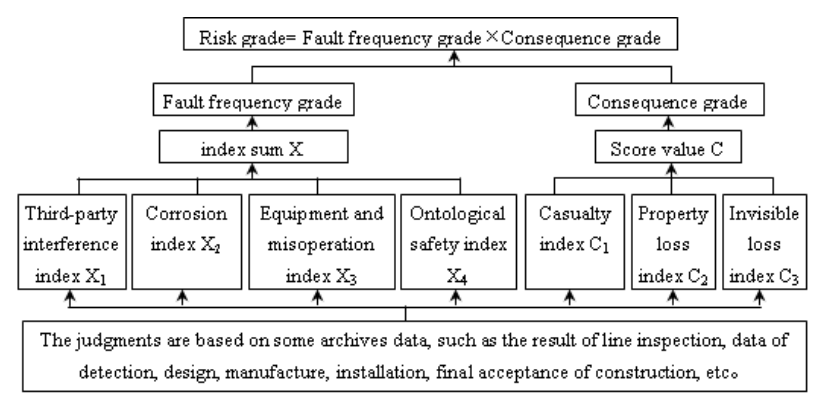

Fig. 1. The Semi-quantitative Risk Assessment Procedure

(1) This correction method is based on Kent analysis method [6, 7].

(2) Adopting semi-quantitative score method, so the score value dose not represent the absolute risk value, and only have the significance of comparison and judgment.

(3) This method only is suitable for the semi-quantitative risk assessment of buried steel gas pipelines.

\section{Analysis of risk factors}

\subsection{Analysis of fault frequency}

According to the feature of urban gas pipelines in China, the correction fault frequency index comprises third-party interference, corrosion, equipment and misoperation, and ontological safety. Fault frequency can be expressed as the weighted sum of these four indexes.

(1) Third-party interference index $X_{1}$ 
Population density, protection and mark of ground facilities, construction and exploration, traffic pressure, casing layer, occupancy on the pipeline, patrol, public education and protection consciousness affect the third-party interference index. Table. 1 gives the grade rules.

\begin{tabular}{|c|c|c|}
\hline Index sort & subclass & Mark range \\
\hline \multirow{9}{*}{$\begin{array}{l}\text { Third-party } \\
\text { interference } \\
\text { index } \mathrm{X}_{1}( \\
30 \%)\end{array}$} & Population density & $0 \sim 5$ \\
\hline & Protection and mark of ground & $0 \sim 5$ \\
\hline & Construction and exploration & $0 \sim 20$ \\
\hline & Traffic pressure & $0 \sim 10$ \\
\hline & Occupancy on the pipeline & $0 \sim 10$ \\
\hline & Casing layer & $0 \sim 5$ \\
\hline & Identification of pipelines & $0 \sim 10$ \\
\hline & Patrol & $0 \sim 20$ \\
\hline & $\begin{array}{l}\text { Public education and protection } \\
\text { consciousness }\end{array}$ & $0 \sim 15$ \\
\hline
\end{tabular}

The values can refer to Kent analysis method.

(2) Corrosion index $X_{2}$

The corrosion influence factors mainly include internal corrosion and external corrosion. Inner corrosion is affected by the quality of gas and internal protective measures. The influence factors are related with external coating, soil environment, cathodic protection system, buried metals around pipeline, stray current, etc. Table. 2 gives the grade rules.

Table.2 The grade rules of corrosion index

\begin{tabular}{c|c|c}
\hline Index sort & subclass & Mark range \\
\hline & Internal protection & $0 \sim 10$ \\
& Quality of gas & $0 \sim 10$ \\
& Cathodic protection & $0 \sim 20$ \\
& External coating & $0 \sim 16$ \\
Corrosion & Soil environment & $0 \sim 12$ \\
index $\mathrm{X}_{2}($ & Age of pipelines & $0 \sim 4$ \\
$30 \%)$ & Buried metals around pipeline & $0 \sim 5$ \\
& Alternating stray current & $0 \sim 4$ \\
& Mechanical corrosion & $0 \sim 5$ \\
& Test pile of potential between & $0 \sim 6$ \\
& pipe and ground & $0 \sim 8$ \\
\hline
\end{tabular}

The values can refer to Kent analysis method.

(3) Equipment and misoperation index $X_{3}$

Equipment and misoperation index is related with function and safety quality of equipment, maintenance of equipment, operation rules and its implement, training and examination, fault prevention device, etc. Table. 3 gives the grade rules.

(4) Ontological safety index $\mathrm{X}_{4}$

The effect factors of ontological safety index include design control of pipelines, device control, installation, additional safety margin, protection measure crossing and span engineer, etc. Table. 4 gives the grade rules.

\begin{tabular}{c|c|c}
\multicolumn{3}{c}{ Table.3 The grade rules of equipment and misoperation index } \\
\hline Index sort & subclass & Mark range \\
\hline & $\begin{array}{c}\text { The function and safety } \\
\text { quality of equipment }\end{array}$ & $0 \sim 10$ \\
$\begin{array}{c}\text { Equipment and } \\
\text { misoperation } \\
\text { index } \mathrm{X}_{3}(\end{array}$ & $\begin{array}{c}\text { Maintenance of equipment } \\
\text { Operation rules and its }\end{array}$ & $0 \sim 35$ \\
implement & $0 \sim 35$ \\
& $\begin{array}{c}\text { Training and examination } \\
\text { Fault prevention device }\end{array}$ & $0 \sim 10$ \\
& $0 \sim 10$ \\
\hline
\end{tabular}

\begin{tabular}{c|c|c} 
Table.4 The grade rules of ontological safety index \\
\hline Index sort & subclass & Mark range \\
\hline \multirow{4}{*}{$\begin{array}{c}\text { Ontological } \\
\text { safety index } \\
(30 \%)\end{array}$} & Design control of pipelines & $0 \sim 4$ \\
\cline { 2 - 3 } & Device control of pipelines & $0 \sim 4$ \\
\cline { 2 - 3 } & Installation of pipelines & $0 \sim 14$ \\
\cline { 2 - 3 } & $\begin{array}{c}\text { Additional safety margin } \\
\text { Protection measure crossing } \\
\text { and span engineer }\end{array}$ & $0 \sim 2$ \\
\cline { 2 - 3 } & Supervision and inspection & $0 \sim 3$ \\
\cline { 2 - 3 } & Supervision & $0 \sim 4$ \\
\cline { 2 - 3 } & $\begin{array}{c}\text { Detection and assessment on } \\
\text { line }\end{array}$ & $0 \sim 4$ \\
\cline { 2 - 3 } & Geological conditions & $0 \sim 50$ \\
\hline
\end{tabular}

(5) Calculation of fault frequency and grade compartmentalization

The final score calculation of fault frequency has been proposed as following equation:

$$
X=a_{1} X_{1}+a_{2} X_{2}+a_{3} X_{3}+a_{4} X_{4}
$$

Where $a_{1} 、 a_{2} 、 a_{3}$ and $a_{4}$ separately are the weights of third-party interference, corrosion, equipment and misoperation, and ontological safety, its values are according to especially region, but must meet $a_{1}+a_{2}+a_{3}+a_{4}=1$.

The final score of fault frequency is between 0 and 100 . The grade can be obtained according to table.5.

\begin{tabular}{c|c|c}
\multicolumn{2}{c}{ Table.5 Grade compartmentalization rules of fault frequency } \\
\hline Grade & Illustration & Score value A \\
A & Almost certain & $80 \leq \mathrm{A}<100$ \\
B & Likely & $60 \leq \mathrm{A}<80$ \\
C & Moderate & $40 \leq \mathrm{A}<60$ \\
D & Unlikely & $20 \leq \mathrm{A}<40$ \\
E & Rare & $0 \leq \mathrm{A} \leq 20$ \\
\hline
\end{tabular}

\subsection{Analysis of fault consequence}

Fault frequency of urban gas pipelines has been proposed as following equation:

$$
C=C_{1}+C_{2}+C_{3}
$$

Where $C_{1}$ is the score of casualties, $C_{2}$ is the score of direct economic losses, and $C_{3}$ is the invisible losses. The conversion method of the score and loss can be referred to Ref. [9].

\subsubsection{Casualties and economic losses area}

Casualties area $A_{1}$ and economic losses area $A_{2}$ are related to some parameters, such as leakage rate, atmospheric stability, diffusion coefficient, concentration distribution of gas, leakage amount, combustion damage mode and its rate, damage area, etc..

API 581 [8] provides reference manifestation after gas leakage and its rate. Researcher may make a correction according to different situations.

3.2.2 The score of casualties $C_{1}$ 
For calculating the score of casualties $C_{1}$, casualties must be determined. Casualties can been written as

$$
N=A_{1} \times \rho_{p} \times f_{p}
$$

Where $\rho_{p}$ is population density, and $\mathrm{fp}$ is personnel exposition frequency coeffi-cient.

Personnel exposition frequency coe-fficient denotes the population mobility effects to population density. Referring to Ref. [9], the score of casualties $C_{1}$ can be proposed as

$$
C_{1}=\left\{\begin{array}{lr}
0 & N \leq 0 \\
20 N \quad 0<N \leq 1 \\
30 N-10 & 1<N \leq 3 \\
5.71 N+62.9 & 3<N \leq 10 \\
1.5 N+105 \quad 10<N \leq 30 \\
150 \quad N>30
\end{array}\right.
$$

\subsubsection{The score of direct economic losses $C_{2}$}

The score of direct economic losses $C_{2}$ can be estimated by direct economic losses $W$, which can be written as

$$
W=A_{2} \times \rho_{o}+W_{d} \times f_{e}+W_{r}
$$

Where $\rho_{o}$ is the property density, $W_{d}$ is user's direct economic losses, $f_{e}$ is the emergency repair coefficient, and $W_{r}$ is the cost of emergency repair.

Referring to Ref. [9], the score of direct economic losses $\mathrm{C}_{2}$ can be proposed as

$$
C_{2}=\left\{\begin{array}{l}
0 \quad W \leq 0 \\
W \quad 0<W \leq 10 \\
0.25 W+7.5 \quad 10<W \leq 50 \\
1.2 W-40 \quad 50<W \leq 100 \\
0.1 W+70 \quad 100<W \leq 500 \\
0.06 W+90 \quad 500<W \leq 1000 \\
150 \quad W>1000
\end{array}\right.
$$

\subsubsection{Assessment of the invisible losses}

Some invisible losses also can be caused by the fault of urban gas pipeline. Invisible losses include:

(1) Critical military installations, Critical main roads, critical electric power facilities, communications facilities, culture relics, etc were severely destroyed.

(2) The accident spot is of political sensitivity.

(3) The accident caused extreme social influence.
If above information is existing, the score of invisible losses will be adjusted to 150 .

\subsubsection{Grade compartmentalization of consequence}

The final score of fault consequence is between 0 and 450 . Consequence grade can be obtained according to table. 6 .

\begin{tabular}{c|c|c}
\multicolumn{2}{c}{ Table.6 The grade compartmentalization rules of fault consequence } \\
\hline Grade & Illustration & Score value $\mathrm{C}$ \\
1 & Insignificant & $0 \leq \mathrm{C}<90$ \\
2 & Minor & $90 \leq \mathrm{C}<180$ \\
3 & Moderate & $180 \leq \mathrm{C}<270$ \\
4 & Major & $270 \leq \mathrm{C}<360$ \\
5 & Catastrophic & $360 \leq \mathrm{C} \leq 450$ \\
\hline
\end{tabular}

\section{Risk matrix and risk sort}

Semi-quantitative risk can be expressed as the multiplication of the frequency grade and consequence grade [5, 10].

Longitudinal axis is used as fault frequency, and abscissa axis as consequence, so risk matrix (Figure.2) is accomplished. Risk value is obtained according to the position of fault frequency and consequence in risk matrix.

\begin{tabular}{|c|l|c|c|c|c|c|}
\cline { 3 - 7 } \multicolumn{2}{c|}{} & \multicolumn{5}{c|}{ Consequences } \\
\hline \multicolumn{2}{|c|}{$\begin{array}{l}\text { Fault } \\
\text { Frequency }\end{array}$} & Insignificant & Minor & Moderate & Major & Catastrophic \\
\cline { 2 - 8 } & 1 & 2 & 3 & 4 & 5 \\
\hline A & $\begin{array}{l}\text { Almost } \\
\text { Certain }\end{array}$ & H & H & E & E & E \\
\hline B & Likely & M & H & H & E & E \\
\hline C & Moderate & L & M & H & E & E \\
\hline D & Unlikely & L & L & M & H & E \\
\hline E & Rare & L & L & M & H & H \\
\hline
\end{tabular}

Fig.2 Risk matrix

\section{Conclusions}

The semi-quantitative risk assessment method is applicable to initial risk assessment of the urban gas pipelines which is planning construction, being constructed, and in service. Through it, high risk of pipelines, risk dynamic sort, risk early-warning and planning accident emergency scheme can be accomplished, and the results of semi-quantitative risk assessment also could provide guidance for pipelines operation, reconstruction and maintenance, etc.

\section{Acknowledgements}

This work was financially supported by the Beijing Finance Project, Research on the technology of On-site Inspection and Accident Investigation for Dangerous and Harmful Gas, and the Project of Beijing Science and Technology Plans, the Accident Warning Equipment and System of Urban Gas Pipelines Based on Strain monitoring.

\section{References}

1. Guo Zhanglin, zhang Huanjun; "The gas pipeline risk assessment base on principal component analysis and BP neural network", Advances in Electronic Engineering, Communication Management, 139(1), 2012, pp. 661-665.
2. W. Kent. Muhlbauer. "Pipeline Risk management manual (second edition)," Beijing: China Petrochemical Press, 2005.

3. Chu Xiaoyan, Shen Shiming. "Risk assessment of pipeline in nature gas utilization engineering in Nanjing City," Oil \& gas storage and transportation, 24(3), 2005, pp.13-16. 
4. Ouk Sub Lee, Dong Hyeok Kim, No Hoon Myoung. "Risk analysis of buried pipeline using probabilistic method", Fracture of Nano and Structures, 2006, pp.713-714.

5. Stewart Bum, Paul Davis, Scott Gould. "Risk analysis for pipeline assets - the use of models for failure prediction in plastics pipelines", Service Life Prediction of Polymeric Materials, 2009, pp.183-204.

6. Wu Wenping, Feng Xia. "Risk acceptance criteria of oil and gas pipelines projects in construction period", Future Communication, Control and Management, (141), 2012, pp. 189-195.
7. Liyang Xie, Zheng Wang, Guangbo Hao, Mingchuan Zhang. "Failure probability estimation of long pipeline", 2008, pp.239-251.

8. API581, "Risk-Based Inspection," 2000.

9. Order 2 of General Administration of Quality Supervision, "Inspection and Quarantine of the People's Republic of China. Accident treatment regulation of special equipment include boiler, pressure vessel and pressure pipe," 2001.

10. A.J.Krasowsky. "The experience on safety, reliability and risk assessment of some Ukrainian, Russian and Latvian Transite pipe lines", 2008, pp.219-231. 